\title{
Supportive care needs of Canadian melanoma patients and survivors
}

by Samuel P. Hetz and Jennifer R. Tomasone

\section{Abstract}

The purpose of this study was to determine the supportive care needs of melanoma patients and survivors in Canada. Thirty-one melanoma patients and survivors completed the Supportive Needs QuestionnaireMelanoma Supplementary Module in addition to questions pertaining to information delivery and screening behaviour. Results demonstrated that the majority of patients in the study are having their needs met (61.1\% of total participant responses). Unfortunately, a substantial proportion of individuals have unmet needs. Of the examined needs, educational and increased informational resource needs were among the greatest reported, particularly among individuals with less education (high school diploma or less). Although overall it appears the majority of needs are being met, more can be done to improve the care of melanoma patients in Canada.

Key words: melanoma, needs assessment, education

Melanoma is the fifth most common cancer in men and sixth most common cancer in women with an age-adjusted incidence rate of 18.3 per 100,000 people per year. Melanoma is a very aggressive form of cancer, occurring 95\% of the time in the skin. Many factors have been identified that increase one's risk of developing melanoma. The greatest risk factor is sunlight and ultraviolet radiation exposure. Fortunately, most melanoma lesions can be detected early through regular and thorough skin examination and by practising sun safety (i.e., using sunscreen regularly, avoiding tanning beds, wearing a hat, etc.) (Markovic et al., 2007). Like other cancers, melanoma has a large psychosocial impact on the patient, which begins at diagnosis. These psychosocial consequences may be partially mitigated through addressing supportive care needs (Wheeler, 2006). More specifically, there is strong support for nurses playing a large role in helping to address these supportive care needs (Wheeler, 2006).

The support needs of larger cancer groups such as breast and lung patients have been evaluated (Fitch \& Steele, 2008; Lindop \& Cannon, 2001). However, for melanoma patients in Canada, supportive needs have not been well examined. Therefore, the purpose of this study was to determine the support needs for melanoma patients in Canada in order to help direct future support services and research.

\section{About the authors}

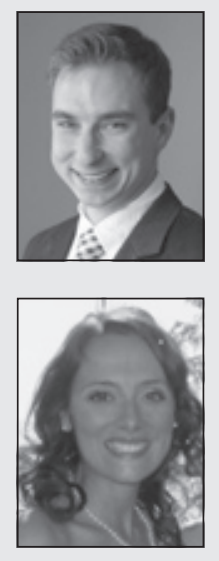

Samuel Hetz, MSc, MD Candidate (Corresponding author), Faculty of Medicine, University of Toronto, Toronto, ON M5S 1A8. Email: sam.hetz@mail.utoronto.ca

Jennifer R. Tomasone, MSc, PhD Candidate, Department of Kinesiology, McMaster University, Hamilton, ON L8S 4K1. Email: tomasojr@mcmaster.ca
In addition, the study attempted to examine how level of education may affect these support needs. Many patients have a lack of knowledge and education following a cancer diagnosis (Treacy \& Mayer, 2000). It has also been demonstrated that individuals with less education generally have higher distress when dealing with a cancer diagnosis (Banks et al., 2010). However, it has also been suggested that such informational needs can be addressed through support systems (Goodwin et al., 2001) and access to educational resources (Schofield et al., 2008).

\begin{tabular}{|c|c|c|}
\hline \multicolumn{3}{|c|}{$\begin{array}{l}\text { Table 1: Participant demographics and melanoma-related } \\
\text { characteristics }\end{array}$} \\
\hline Characteristic & $\mathbf{n}$ & Value \\
\hline Current age (years \pm SD) & 28 & $49.86 \pm 10.97$ \\
\hline Age at melanoma diagnosis (years \pm SD) & 30 & $44.37 \pm 10.00$ \\
\hline Location of primary tumour & 31 & \\
\hline Torso (head, chest, stomach) & & $25(80.6)$ \\
\hline Limbs (shoulder, hand, leg) & & $0(0.0)$ \\
\hline Head or neck & & $4(12.9)$ \\
\hline Unknown & & $2(6.4)$ \\
\hline Sex & 31 & \\
\hline Male & & $11(35.5)$ \\
\hline Female & & $20(64.5)$ \\
\hline Current stage of cancer & 29 & \\
\hline No evidence of disease/remission & & $14(48.3)$ \\
\hline Stage 1 & & $1(3.4)$ \\
\hline Stage 2 & & $3(10.3)$ \\
\hline Stage 3 & & $3(10.3)$ \\
\hline Stage 4 & & $8(27.6)$ \\
\hline Highest education completed & 31 & \\
\hline High school or less & & $8(25.8)$ \\
\hline Trade/vocational & & $1(3.2)$ \\
\hline University/college & & $21(67.7)$ \\
\hline Other & & $1(3.2)$ \\
\hline Current employment status & 31 & \\
\hline Paid (part or full time) & & $13(41.9)$ \\
\hline Retired & & $5(16.1)$ \\
\hline Cannot work due to illness & & $4(12.9)$ \\
\hline Unemployed & & $1(3.2)$ \\
\hline Unpaid work (homemaker, volunteer) & & $3(9.7)$ \\
\hline Other & & $4(12.9)$ \\
\hline No response & & $1(3.2)$ \\
\hline $\begin{array}{l}\text { Note: All values are } n(\%) \text { except for curren } \\
\text { melanoma diagnosis, which are } M \pm S D \text {. So } \\
\text { declined to respond to certain questions; } \\
\text { characteristics. }\end{array}$ & & $\begin{array}{l}\text { age at } \\
\text { bants } \\
1 \text { for some }\end{array}$ \\
\hline
\end{tabular}




\section{Methods}

This study was a cross-sectional, quantitative study examining the support needs of melanoma patients and survivors. Sixty-one melanoma patients from across Canada were contacted via email with a consent form and a link to an online questionnaire. All patients were current or past members of the Melanoma Network of Canada (MNC), a national, patient-led organization that aims to provide current and accurate melanoma information and resources to melanoma patients and their caregivers (www.melanomanetwork.ca). Although the MNC consists of health professionals (nurses, family physicians, dermatologists) and people without a melanoma diagnosis (family members, friends), only those who currently have or have had a previous melanoma diagnosis were asked to participate. Furthermore, as the survey was electronic, individuals who did not have email access were not contacted. The consent form was written in English only and was communicated at a Grade 8 reading level to ensure it was comprehensible by the majority of participants.

The online questionnaire consisted of three sections. The first section consisted of general demographic information. This was important to determine the types of needs for different demographic groups such as level of education, age, and current stage of disease. The second section of the questionnaire was a melanoma-specific needs survey (Supportive Needs Questionnaire-Melanoma Supplementary Module) that asks participants to report their needs assessment over the past month. The Melanoma Supplementary Module was developed by the Supportive Care Review Group and the Centre for Health Research and Psycho-oncology (Supportive Care Support Group: Bonevski et al., 2000; Sanson-Fisher et al., 2000), and originated from the Cancer Needs Questionnaire, which has been validated as an effective tool for determining support needs of cancer patients (Cossich, Schofield, \& McLachlan, 2004). The third section consisted of questions pertaining to additional informational needs and screening behaviours.

The questionnaire was converted into an online format using Fluid Surveys (www.fluidsurveys.com). Other than formatting modifications, the questionnaires were not altered. Fluid Surveys allows for confidential and anonymous data collection in a timely fashion. Moreover, online questionnaires have been found to have a higher response rate than questionnaires via mail (Lonsdale, Hodge, \& Rose, 2006).
Following the data collection, analyses were conducted using Statistical Package for the Social Sciences (SPSS version 17.0, Chicago, IL). First, responses from the questionnaires were analyzed to determine the most sought after needs of the patients. Specifically, these analyses were conducted by examining how many individuals reported specific needs (i.e., frequency of each reported need). Second, analyses of variance (ANOVAs) and Chi-Square tests were conducted to determine if demographic variables such as age, sex, education level, and stage of disease, predicted the need for the educational, emotional, and physical support services.

\section{Results}

Of the 61 recruited participants, 31 accessed the survey and completed the majority of the demographic information (50.8\% response rate). More women than men completed the survey ( $n=20$ vs. 11). Mean age at the time of survey completion was $49.9 \pm 11.0$ years, while mean age at the time of melanoma diagnosis was $44.4 \pm 10.0$ years. For statistical analyses, education was further categorized into 'High School or Less' $(n=8)$ and 'Post-Secondary Education' $(n=23)$. Complete participant demographic information can be found in Table 1.

Complete results from the Supportive Needs QuestionnaireMelanoma Supplementary Module can be found in Table 2. 61.1\% of participant responses indicated that they were satisfied or that the particular need in question was not applicable to them, while $21.7 \%$ of participant responses indicated a moderate or high level of supportive need. The highest reported supportive needs (those reporting moderate or high level of need) were in regards to access to a second opinion (44.0\%), information about non-surgical treatment of melanoma (24.0\%), information about how and when to check for skin changes (24.0\%), and information about unwanted effects of surgical treatment (24.0\%). Finally, $24.0 \%$ and $20.8 \%$ reported a moderate or high need with respect to skin soreness and lymphedema, respectively.

Using separate ANOVAs, it was found that individuals without postsecondary education (i.e., those with a high school level education or less) have a higher need for information about surgical treatment of the skin $[F(1,4.72)=1.67 \pm 0.39$ vs. $6.84 \pm 0.22, p=.04]$, surgical removal of lymph nodes $[F(1,10.40)=2.33 \pm 0.45$ vs. $0.68 \pm 0.25, p=.004]$, information about non-surgical treatments $[F(1,7.88)=2.83 \pm 0.52$ vs.

\begin{tabular}{|c|c|c|c|c|c|}
\hline In the last month, what was your level of need for help with: & $\begin{array}{c}\text { Not } \\
\text { applicable }\end{array}$ & Satisfied & $\begin{array}{l}\text { Low } \\
\text { need }\end{array}$ & $\begin{array}{l}\text { Moderate } \\
\text { need }\end{array}$ & $\begin{array}{l}\text { High } \\
\text { need }\end{array}$ \\
\hline Skin soreness & $12(48.0)$ & $4(16.0)$ & $3(12.0)$ & $5(20.0)$ & $1(4.0)$ \\
\hline Lymphedema (swelling of a limb after gland dissection) & $11(45.8)$ & $4(16.7)$ & $4(16.7)$ & $3(12.5)$ & $2(8.3)$ \\
\hline More information about the risk of recurrence of melanoma & $3(11.5)$ & $11(42.3)$ & $7(26.9)$ & $2(7.7)$ & $3(11.5)$ \\
\hline To be informed about the need for surgical treatment of melanoma of the skin & $10(40.0)$ & $10(40.0)$ & $3(12.0)$ & $1(4.0)$ & $1(4.0)$ \\
\hline To be informed about the need for surgical removal of lymph nodes & $11(44.0)$ & $7(28.0)$ & $3(12.0)$ & $2(8.0)$ & $2(8.0)$ \\
\hline $\begin{array}{l}\text { More information about non-surgical treatment of melanoma (chemotherapy, } \\
\text { immunotherapy) }\end{array}$ & $8(32.0)$ & $5(20.0)$ & $6(24.0)$ & $2(8.0)$ & $4(16.0)$ \\
\hline $\begin{array}{l}\text { More information about possible outcomes when melanoma has spread from } \\
\text { the skin }\end{array}$ & $6(24.0)$ & $5(20.0)$ & $8(32.0)$ & $3(12.0)$ & $3(12.0)$ \\
\hline To be informed about things you can do for skin protection & $5(20.0)$ & $14(56.0)$ & $2(8.0)$ & $0(0.0)$ & $4(16.0)$ \\
\hline To be informed about how and when to check your skin for changes & $3(12.0)$ & $11(44.0)$ & $5(20.0)$ & $3(12.0)$ & $3(12.0)$ \\
\hline Access to a second opinion about your condition or treatment if you want one & $6(24.0)$ & $5(20.0)$ & $3(12.0)$ & $7(28.0)$ & $4(16.0)$ \\
\hline More information about the unwanted effects of surgical treatment & $4(16.0)$ & $12(48.0)$ & $3(12.0)$ & $2(8.0)$ & $4(16.0)$ \\
\hline Information about how to control pain & $8(32.0)$ & $8(32.0)$ & $4(16.0)$ & $2(8.0)$ & $2(12.0)$ \\
\hline Total & $87(29.0)$ & $96(32.1)$ & $51(17.1)$ & $32(10.7)$ & $33(11.0)$ \\
\hline
\end{tabular}


$1.16 \pm 0.29, p=.01]$, information about the outcomes when the melanoma has spread from the $\operatorname{skin}[F(1,24.99)=3.33 \pm 0.38$ vs. $1.16 \pm 0.21$, $p=.0001]$, and information about how to control pain $[F(1,7.04)=2.50$ \pm 0.49 vs. $1.00 \pm 0.27, p=.01]$. No other relationships between demographic information (i.e., age, current stage of disease) and results from the Melanoma Supplementary Module were found.

Additional informational needs and screening behaviour characteristics can be found in Table 3. The majority of patients reported that they were not provided with any informational tools upon diagnosis $(66.7 \%)$, did not receive sufficient information regarding treatment options (60\%), and did not receive sufficient information regarding diagnosis and prognosis (50\%). However, the majority of patients (85\%) do feel comfortable asking their medical team and physician questions about their diagnosis and treatment. Using separate Pearson Chi-Square tests it was found that individuals without post-secondary education felt less comfortable asking their medical team and physician questions about their diagnosis and treatment $\chi^{2}(1, n=20)=4.80, p=.028$. These individuals also conduct regular self-checks to screen for melanoma or recurrence less often if at all $\chi^{2}(2, n=21)=10.57, p=.005$. Additional informational needs and screening behaviour characteristics results were not associated with any other demographic characteristics.

\section{Discussion}

The purpose of this study was to elucidate the supportive care needs of melanoma patients and survivors to help guide future support initiatives and research. Fortunately, the majority of patients are having their needs met. However, there is still a substantial proportion of melanoma patients and survivors who have unmet or poorly satisfied needs. Results from the Supportive Needs QuestionnaireMelanoma Supplementary Module suggest that up to $44 \%$ of individuals report a moderate or high demand with melanoma specific needs. It appears from this survey that lack of information regarding treatment options, outcomes, and monitoring are the greatest reported needs. This issue may be partially addressed by increasing the amount of educational material available to patients, as well as increasing communication between the health care team and patients. Furthermore, suggesting support and advocacy groups at the time of diagnosis may also help to fill the gaps in educational needs. This responsibility lies not only with nurses, but the entire health care team.

Interestingly, individuals with less education (i.e., no post-secondary education) had a greater need for information and educational resources. This greater need may not be due to a lack of education, per se, but that these individuals are not as independent in seeking out or interpreting additional information compared to those with higher education. However, no known study to date has evaluated this hypothesis. These findings suggest that individuals with less education may benefit the most from additional informational material and communication with health care professionals. Level of education should be kept in mind when a nurse or other health professional is interacting with patients, specifically when providing information about diagnosis, treatment options, and prognosis.

The most concerning results were collected from the additional informational needs and screening behaviour characteristics section of the survey. The majority of patients reported that they were not provided with any informational tools upon diagnosis, and that they did not receive sufficient information regarding their diagnosis, prognosis, and treatment options. Although given survey item. the responsibility for providing this information sits primarily with the health care team at time of diagnosis, advocacy organizations and support groups can help fill the gaps in educational resources. In addition to providing additional information, it appears that further advocacy is necessary to ensure patients are receiving the information they require at the time of diagnosis and throughout treatment. However, since these data are self-reported, it is possible that patients were presented with informational material at the time of diagnosis, but simply do not remember (Jansen et al., 2008).

Not only did individuals without post-secondary education have a greater need for information and educational resources, it was found that these individuals also felt less comfortable asking their medical team and physician questions about their diagnosis and treatment. It is possible that they feel their questions are naïve, will come across as being uneducated, or simply do not know which questions to ask. It is important for the health care team to prompt the patient to express his/her concerns in order to promote open communication. Additionally, individuals without post-secondary education also conduct regular self-checks to screen for melanoma or recurrence less often than individuals with post-secondary education, further suggesting the need for additional information for this subgroup of patients.

Despite the important contributions of this study to understanding the supportive care needs of melanoma patients and survivors, a few limitations are worth mentioning. First, data were only collected from MNC members. Although this cohort was easily accessible, most individuals were not newly diagnosed patients (current age was approximately five years older than age at melanoma diagnosis). Collecting information from individuals with a long latent period from diagnosis may increase response bias. Furthermore, accessing this group exclusively also resulted in a small sample size, with a disproportionate number of men and women participating. Second, the online data collection tool prohibited anyone without an email address from accessing the survey. This perhaps biased the results to include a younger cohort, as well as individuals who were actively seeking support. Finally, the questionnaire examined current needs or needs within the last month. It is very likely that needs change over time with a cancer diagnosis. For example, the need for information regarding treatment options is likely greatest soon after diagnosis rather than years afterwards when there is no evidence of disease. Given the cross-sectional nature of the study, as well as a small sample size, the changes in needs over time could not be examined. Examining how support needs of melanoma patients change throughout time should be a topic of future research.

Table 3. Frequency (and percentage) of additional informational needs and screening behaviour responses

\begin{tabular}{|l|c|c|}
\hline & Yes $n$ (\%) & No $n$ (\%) \\
\hline $\begin{array}{l}\text { When you were first diagnosed with melanoma, were you provided } \\
\text { with any informational tools, binders, pamphlets, or websites to } \\
\text { assist you in understanding your diagnosis? }\end{array}$ & $7(33.3)$ & 14 (66.7) \\
\hline $\begin{array}{l}\text { Throughout your treatment, do you feel you received sufficient } \\
\text { information regarding your diagnosis and prognosis? }\end{array}$ & $10(50.0)$ & $10(50.0)$ \\
\hline $\begin{array}{l}\text { Throughout your treatment, do you feel you received sufficient } \\
\text { information regarding the full range of treatment options? }\end{array}$ & 8 (40.0) & $12(60.0)$ \\
\hline $\begin{array}{l}\text { Did you feel comfortable enough to ask your medical team/doctor } \\
\text { questions concerning your diagnosis or treatment? }\end{array}$ & $17(85.0)$ & $3(15.0)$ \\
\hline $\begin{array}{l}\text { Do you conduct regular self-checks to screen for melanoma, skin } \\
\text { cancers or a recurrence? }\end{array}$ & $17(81.0)$ & $4(19.0)$ \\
\hline
\end{tabular}

Note: Some participants declined to respond to certain questions; hence, $n=20-21$ for any

a Three of the four participants who reported "No" do not conduct regular self-checks because they do not know what they are looking for. 
This study is the first of its kind to examine the supportive care needs of melanoma patients in Canada. Although descriptive, this study found that informational and education resources were among the greatest reported needs. Many participants also need additional screening regularly. Specifically, it appears that individuals with less education (high school or less) have the highest need for educational and information resources. It has been suggested that this specific sub-group of patients be targeted at time of diagnosis and throughout treatment. While it appears the majority of needs are being met, it is apparent from this study that more can be done to improve the supportive care of melanoma patients in Canada.

\section{Implications for nursing}

Nurses play a vital role in providing health care to melanoma patients throughout the course of their illness. From this study, a few implications can be drawn. First, ensuring that nurses are part of the educational framework-and are in a position to provide information and educational resources-is essential (Mills \& Sullivan, 1999). Second, melanoma patients need additional information and educational resources (beyond what they are currently receiving), especially regarding treatment options, outcomes, and monitoring. The type, amount, and breadth of information needed varies both between individuals (e.g., whether or not they have completed post-secondary education) and within individuals throughout the cancer experience (van der Molen, 2000). The informational needs of a given patient should be assessed upon or soon after diagnosis, and the information given should be tailored to reflect the patient's needs and individual situation (including their cultural background, religious beliefs, support

\section{REFERENCES}

Banks, E., Byles, J.E., Gibson, R.E., Rodgers, B., Latz, I.K., Robinson, I.A., ... Jorm, L.R. (2010). Is psychological distress in people living with cancer related to the fact of diagnosis, current treatment or level of disability? Findings from a large Australian study. Medical Journal of Australia,193(5 Suppl.), S62-S67.

Bonevski, B., Sanson-Fisher, R.W., Girgis, A., Burton, L., Cook, P., Boyes, A., ... the Supportive Care Review Group. (2000). Evaluation of an instrument to assess the needs of patients with cancer. Cancer, 88, 217-25. doi:10.1002/(SICI)10970142(20000101)88:1<217::AID-CNCR29>3.0.CO;2-Y

Cossich, T., Schofield, P., \& McLachlan, S.A. (2004). Validation of the cancer needs questionnaire-short form version in ambulatory cancer setting. Quality of Life Research, 13, 1225-33. doi:10.1023/ B:QURE.0000037496.94640.d9

Deeny, K., \& McGuigan, M. (1999). The value of the nurse-patient relationship in the care of cancer patients. Nursing Standard 13, 45-47.

Fitch, M.I., \& Steele, R. (2008). Supportive care needs of women with lung cancer. Canadian Oncology Nursing Journal, 18(1), 5-12. doi:10.1089/cbr.2010.0902

Goodwin, P.J., Leszcz, M., Ennis, M., Koopmans, J., Vincent, L., Guther H., ... Hunter, J. (2001). The effect of group psychosocial support on survival in metastatic breast cancer. The New England Journal of Medicine, 345, 1719-1726.

Jansen, J., Butow, P.N., van Weert, J.C., van Dulmen, S., Devine, R.J., Heeren, T.J., ... Tattersall, M.H. (2008). Does age really matter? Recall of information presented to newly referred patients with cancer. Journal of Clinical Oncology, 26, 5450-5457. doi:10.1200/ JCO.2007.15.2322

Lindop, E., \& Cannon, S. (2001). Evaluating the self-assessed support needs of women with breast cancer. Journal of Advanced Nursing, 34, 760-771. doi:10.1046/j.1365-2648.2001.01806.x

Lonsdale, C., Hodge, K., \& Rose, A. (2006). Pixels vs. paper: Comparing online and traditional survey methods in sports psychology. Journal of Sport and Exercise Psychology, 28, 100-108. networks, and the quality of rapport they have with their health care team) (Deeny \& McGuigan, 1999). Single point education (i.e., pamphlet, or single discussion) may not be sufficient. Realizing that informational needs fluctuate, ongoing informational support would help ensure that the patient's needs continue to be met once initial treatment is over. For example, providing multiple routes of information at different times (i.e., pamphlets, information workshops on how to monitor for new lesions, small group questions and answer sessions), as well as early referral to an advocacy group (i.e., Melanoma Network of Canada), could help with the fluctuating informational needs of melanoma survivors. Third, particular attention needs to be given to individuals with suspected or documented lower levels of education. From this study it was apparent that these individuals have a greater need for educational resources, feel less comfortable asking their health care team questions, as well as perform regular skin exams less often if at all. Ensuring that these individuals are both identified early and have additional interaction with nursing staff as well as other members of the health care team is crucial. Specifically, ensuring that these individuals feel more comfortable with the health care team, as well as know how to monitor their skin for additional melanoma lesions, is of particular concern.

\section{Acknowledgement}

We would like to specifically thank Debbie Lawrie, $R N$, from the Melanoma Clinic at the Odette Cancer Centre, at Sunnybrook Hospital, Toronto, Ontario, for her assistance and suggestions while preparing this manuscript for publication. We would also like to thank the many nurses who were undoubtedly part of the health care that each participant in this study received.

Markovic, S.N., Erickson, L.A., Rao, R.D., Weenig, R.H., Prockaj, B.A., Bardia, A, ... Melanoma Study Group of the Mayo Clinic Cancer Center. (2007). Malignant melanoma in the 21st century, part 1: Epidemiology, risk factors, screening, prevention, and diagnosis. Mayo Clinic Proceedings, 82, 364-380.

Mills, M.E., \& Sullivan, K. (1999). The importance of information giving for patients newly diagnosed with cancer: A review of the literature. Journal of Clinical Nursing, 8, 631-642.

Sanson-Fisher, R.W., Girgis, A., Boyes, A., Bonevski, B., Burton, L., Cook, P., ... The Supportive Care Review Group. (2000). The unmet need supportive care needs of patients with cancer. Cancer, 88, 226-237.

Schofield, P., Jefford, M., Carey, M., Thomson, K., Evans, M., Baravelli, C., \& Aranda, S. (2008). Preparing patients for threatening medical treatments: Effects of a chemotherapy educational DVD on anxiety, unmet needs, and self-efficacy. Supportive Care in Cancer, 16, 37-45. doi:10.1007/s00520-007-0273-4

The Melanoma Network of Canada. Retrieved from www. melanomanetwork.ca

Treacy, J.T., \& Mayer, D.K. (2000). Perspectives on cancer patient education. Seminars in Oncology Nursing, 16, 47-56. doi:10.1016/ S0749-2081(00)80007-8

Wheeler, T. (2006). Psychological consequences of malignant melanoma: Patients' experiences and preferences. Nursing Standard, 21, 42-46.

van der Molen, B. (2000). Relating information-needs to the cancer experience: 1. Jenny's story: A cancer narrative. European Journal of Cancer Care 9, 41-47.

\section{Suppliers}

Fluid Surveys. www.fluidsurveys.com, Chide.it Inc., 1729 Bank Street-Suite 200, Ottawa, ON K1V 7Z5

SPSS Statistics 17.0. SPSS Inc, 233 S Wacker Dr, 11th Fl, Chicago, IL 60606 